\title{
Impact of Naja nigricollis Venom on the Production of Methaemoglobin
}

\author{
Harry F. Williams ${ }^{1,+}{ }^{+}$Paul Hayter ${ }^{2,+}$, Divyashree Ravishankar ${ }^{1}{ }^{\circledR}$, Anthony Baines ${ }^{3}$, \\ Harry J. Layfield ${ }^{1}$, Lorraine Croucher ${ }^{4}$, Catherine Wark ${ }^{4}$, Andrew B. Bicknell ${ }^{5}$, Steven Trim ${ }^{2, *}$ \\ and Sakthivel Vaiyapuri ${ }^{1, *(1)}$ \\ 1 School of Pharmacy, University of Reading, Reading RG6 6UB, UK; h.f.williams@pgr.reading.ac.uk (H.F.W.); \\ d.ravishankar@reading.ac.uk (D.R.); h.j.layfield@reading.ac.uk (H.J.L.) \\ 2 Venomtech, Discovery Park, Sandwich, Kent CT13 9ND, UK; paul.hayter@talktalk.net \\ 3 School of Biosciences, University of Kent, Kent CT2 7NZ, UK; a.bains@venomtech.co.uk \\ 4 BMG LabTech, Buckinghamshire HP19 8JR, UK; lorraine.croucher@bmglabtech.com (L.C.); \\ catherine.wark@bmglabtech.com (C.W.) \\ 5 School of Biological Sciences, University of Reading, Reading RG6 6UB, UK; a.b.bicknell@reading.ac.uk \\ * Correspondence: s.trim@venomtech.co.uk (S.T.); s.vaiyapuri@reading.ac.uk (S.V.) \\ + Authors contributed equally to this work.
}

Received: 19 October 2018; Accepted: 14 December 2018; Published: 15 December 2018

\begin{abstract}
Snakebite envenomation is an affliction currently estimated to be killing upwards of 100,000 people annually. Snakebite is associated with a diverse pathophysiology due to the magnitude of variation in venom composition that is observed worldwide. The haemolytic (i.e., lysis of red blood cells) actions of snake venoms are well documented, although the direct impact of venoms on haemoglobin is not fully understood. Here we report on the varied ability of a multitude of snake venoms to oxidise haemoglobin into methaemoglobin. Moreover, our results demonstrate that the venom of an elapid, the black necked spitting cobra, Naja nigricollis, oxidises oxyhaemoglobin $\left(\mathrm{Fe}^{2+}\right)$ into methaemoglobin $\left(\mathrm{Fe}^{3+}\right)$ in a time- and concentration-dependent manner that is unparalleled within the 47 viper and elapid venoms evaluated. The treatment of venom with a reducing agent, dithiothreitol (DTT) is observed to potentiate this effect at higher concentrations, and the use of denatured venom demonstrates that this effect is dependent upon the heat-sensitive proteinaceous elements of the venom. Together, our results suggest that Naja nigricollis venom appears to promote methaemoglobin production to a degree that is rare within the Elapidae family, and this activity appears to be independent of proteolytic activities of venom components on haemoglobin.
\end{abstract}

Keywords: Snakebite; venom; methaemoglobin; haemoglobin; neglected tropical disease; spitting cobra

Key Contribution: We demonstrate the impact of Naja nigricollis (the black necked spitting cobra) venom in the oxidation of haemoglobin to methaemoglobin, which is a toxic species capable of causing a range of additional issues to envenomed victims.

\section{Introduction}

Snakebite envenomation is considered to be a major neglected tropical disease. It is estimated to affect nearly five million people and result in approximately 100,000 deaths annually [1]. It is a crisis that predominantly impacts upon people living in rural areas of developing nations, and can induce major socio-economic ramifications [2,3]. Despite the significant impact on the health and well-being of humans, much remains unknown about the different toxic proteins and peptides that are the major components of snake venoms [4]. Venomous snakes have been classified into several 
families and sub families, but the vast majority of deaths occur as a result of bites from those found in Viperidae (Vipers) and Elapidae (Elapids). These two families are very different; vipers are typically ambush predators that inject a venom composed mainly of large proteins that predominantly affect haemostasis, while elapids are generally more active hunters, with venoms containing fewer of these haemotoxic components but instead dominated by neurotoxic and cytotoxic proteins and peptides [5]. Thus elapids are less commonly associated with haemostatic disturbances.

A range of biological activities have been found to be induced by snake venom components, with many of these proteins targeting the blood, haemostasis and cardiovascular system [6,7]. Serine proteases and metalloproteases are the most abundant proteins found in viper venoms and they exhibit various haemotoxic effects. Metalloproteases are able to affect the basement membrane of blood vessels via collagenolytic activity [8], and several other venom components inhibit or activate platelets by different mechanisms [9-11]. As well as interacting with platelets and blood vessels, many venom proteins affect the blood coagulation cascade via coagulatory or anti-coagulatory effects [12]. An array of different proteins capable of causing haemolysis also exist within snake venoms, for example, the enzymatic phospholipase A2 (PLA2) which directly cleave the phospholipid bilayer, and the hydrophobic three-finger toxins, which can bind to the cell membrane to promote lysis [13]. Indeed, haemolysis can take place to such a degree that haemolytic anaemia has developed in some recorded cases of snakebites [14]. Haemolysis is a well-known effect of several snake venoms, although their direct effects on red blood cells (RBCs) and their components are not fully understood, especially given the oxidative stress typically observed as a secondary effect of certain snake bites [15-17].

In addition to natural intra- or extravascular haemolysis (approximately $10 \%$ of RBCs will lyse as a consequence of wear and tear) and direct lysis by venom components, haemolysis also takes place as a result of the venom-induced local tissue damage which produces reactive oxygen (ROS) and nitrogen species that contribute to oxidative damage and further lysis of cells [16]. The release of haemoglobin $(\mathrm{Hb})$ into the plasma following haemolysis triggers inflammation and oxidative stress as well as impairing endothelial function. Excessive plasma $\mathrm{Hb}$ levels is called haemoglobinemia and it can induce extreme nitric oxide consumption and clinical sequelae including haemolysis-associated vasculopathies and endothelial dysfunction [18]. Free plasma $\mathrm{Hb}$ is bound rapidly by haptoglobin in order to inhibit its oxidative activity, and this complex is rapidly removed by the mononuclear phagocytic system, particularly the spleen [19]. After plasma haptoglobin is saturated, the excessive $\mathrm{Hb}$ is filtered out by the kidneys. Frequently, during envenomation these organs are already under pressure due to decreased renal blood flow as a result of ischaemia, thrombotic microangiopathy and rhabdomyolysis. These in turn cause myoglobin deposits in renal tubules [4] and together lead to acute kidney injury, which is a main systemic complication and is frequently the cause of death in viper bites [20].

$\mathrm{RBC}$ are essential for the transportation of oxygen to the tissues and delivery of $\mathrm{CO}_{2}$ (or dissolved $\mathrm{HCO}_{3}{ }^{-}$) to the lungs; they are entirely dependent upon the oxygen transport protein, $\mathrm{Hb}$. This protein relies on a prosthetic ferrous $\left(\mathrm{Fe}^{2+}\right)$ haem group, the ferric oxidation of which renders the protein (termed as methaemoglobin (MetHb)) unable to transport oxygen $\left(\mathrm{Fe}^{3+}\right)$, a process which has already been observed in specific snake venoms [21]. This process takes place at a very low rate naturally, and $\mathrm{Met} H \mathrm{~b}$ is maintained at $<1 \%$ by rapid reduction to the ferrous form, a process catalysed by the enzyme methaemoglobin reductase [22]. Through this reaction, a superoxide free radical is generated but is quickly dismutated via the enzyme superoxide dismutase forming $\mathrm{H}_{2} \mathrm{O}_{2}$ and $\mathrm{O}_{2}$ [23]. Methaemoglobinemia occurs when the levels of MetHb occur above $2 \%$ and serious neurological and cardiovascular symptoms can develop as a result of hypoxia with levels of approximately $15 \%$ and above [24].

Venom-induced oxidative stress appears to be an effect of envenomation that anti-snake venom (ASV) (the only available treatment for snakebite envenoming) fails to ameliorate [25], and may actually exacerbate [21]. These effects are reduced by the co-administration of melatonin, an anti-oxidant agent, along with ASV, and there is evidence to suggest a reduction in methaemoglobinemia as a result $[16,21]$. However, the scale of oxidative stress and other effects of venom components on the functions of RBCs 
and $\mathrm{Hb}$ are yet to be studied in detail. Here, we report the screening of a large number of snake venoms and specifically characterise the effect of the venom of Naja nigricollis (N. nigricollis) to determine its impact on the production of MetHb.

\section{Results}

\subsection{A Range of Snake Venoms Induce the Oxidation of $\mathrm{Hb}$}

The ability of venoms to oxidise $\mathrm{Hb}$ into MetHb has been reported within the family of Viperidae $[15-17,26]$. Here, we screened 47 different viper (30) and elapid (17) venoms from the targeted venom discovery array for the cardiovascular system $\left(\mathrm{T}-\mathrm{VDA}^{\mathrm{CV}}\right)$ in order to determine the impact of these on MetHb production. The venoms $(0.2 \mathrm{mg} / \mathrm{mL})$ were mixed with an equal volume of ovine $\mathrm{Hb}$ (the supernatant of lysed ovine RBCs) and incubated for $16 \mathrm{~h}$ prior to measuring the absorbance at $500 \mathrm{~nm}$ and $630 \mathrm{~nm}$ (i.e., absorbance maxima for MetHb). An overnight period of $16 \mathrm{~h}$ was used in the experiments in order to determine the maximum impact of venom on $\mathrm{MetHb}$ production. The data suggest that $\mathrm{Hb}$ oxidising activity is common among several viper venoms but this is a rare phenomenon for an elapid snake venom (Figure 1). Notably, the large increase in absorbance observed in many viper venoms was only evident in the venom of one elapid, N. nigricollis. As this is a unique feature observed in N. nigricollis venom, we have analysed this effect in greater detail.

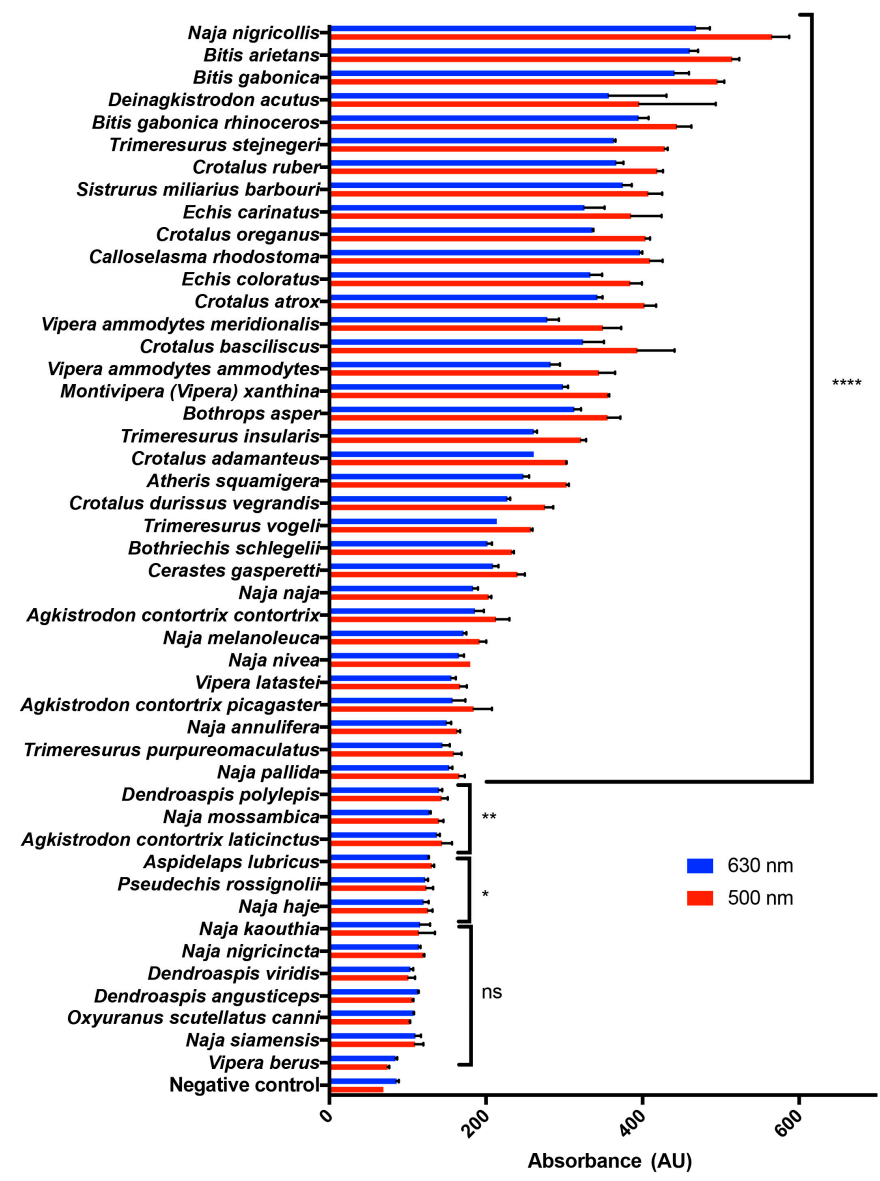

Figure 1. Impact of T-VDA ${ }^{\mathrm{CV}}$ venom array on MetHb production. Whole snake venoms $(0.2 \mathrm{mg} / \mathrm{mL})$ from the T-VDA ${ }^{C V}$ array (Venomtech Limited, UK) targeting the cardiovascular system were dispensed into 96-well micro titre plates, mixed with an equal volume of ovine $\mathrm{Hb}$, and incubated at $37^{\circ} \mathrm{C}$ for $16 \mathrm{~h}$. The absorbance was measured at $500 \mathrm{~nm}$ and $630 \mathrm{~nm}$ (i.e., the peaks typically observed for MetHb) by spectrofluorimetry (FLUOstar Optima, BMG Labtech) at $16 \mathrm{~h}$. Data represent mean $\pm \operatorname{SEM}(n=3)$, and the $p$ values (all the values were compared to the negative control [PBS]) were calculated by One-way ANOVA followed by post-hoc Tukey's test using GraphPad Prism $\left({ }^{*} p<0.05,{ }^{* *} p<0.01\right.$, and $\left.{ }^{* * * *} p<0.0001\right)$. 


\subsection{Naja Nigricollis Venom Is Significantly Increasing MetHb Production}

To determine the effect of $\mathrm{N}$. nigricollis venom on MetHb production, additional experiments were performed using ovine $\mathrm{Hb}$. N. nigricollis venom $(10 \mathrm{mg} / \mathrm{mL}$ was used to achieve a maximum response) was incubated with ovine $\mathrm{Hb}$ and the level of absorbance for $\mathrm{Hb}$ and MetHb was measured every $2 \mathrm{~h}$ for $16 \mathrm{~h}$. The venom displayed a time-dependent decrease in absorbance at $540 \mathrm{~nm}$ and $570 \mathrm{~nm}$ (i.e., peaks observed for $\mathrm{Hb}$ ) with a corresponding time-dependent increase in absorbance at $500 \mathrm{~nm}$ and $630 \mathrm{~nm}$ (i.e., peaks typical of MetHb) (Figure 2A,B). Similarly, the increasing concentrations of N. nigricollis venom suggest that this venom-induced impact on $\mathrm{MetHb}$ production is also concentration-dependent (Figure 2C,D). Therefore, an optimal concentration of $0.2 \mathrm{mg} / \mathrm{mL}$ venom was used in other experiments in this study. Together these results suggest that the N. nigricollis venom is promoting the oxidation of oxyhaemoglobin to MetHb in a time- and concentration-dependent manner.
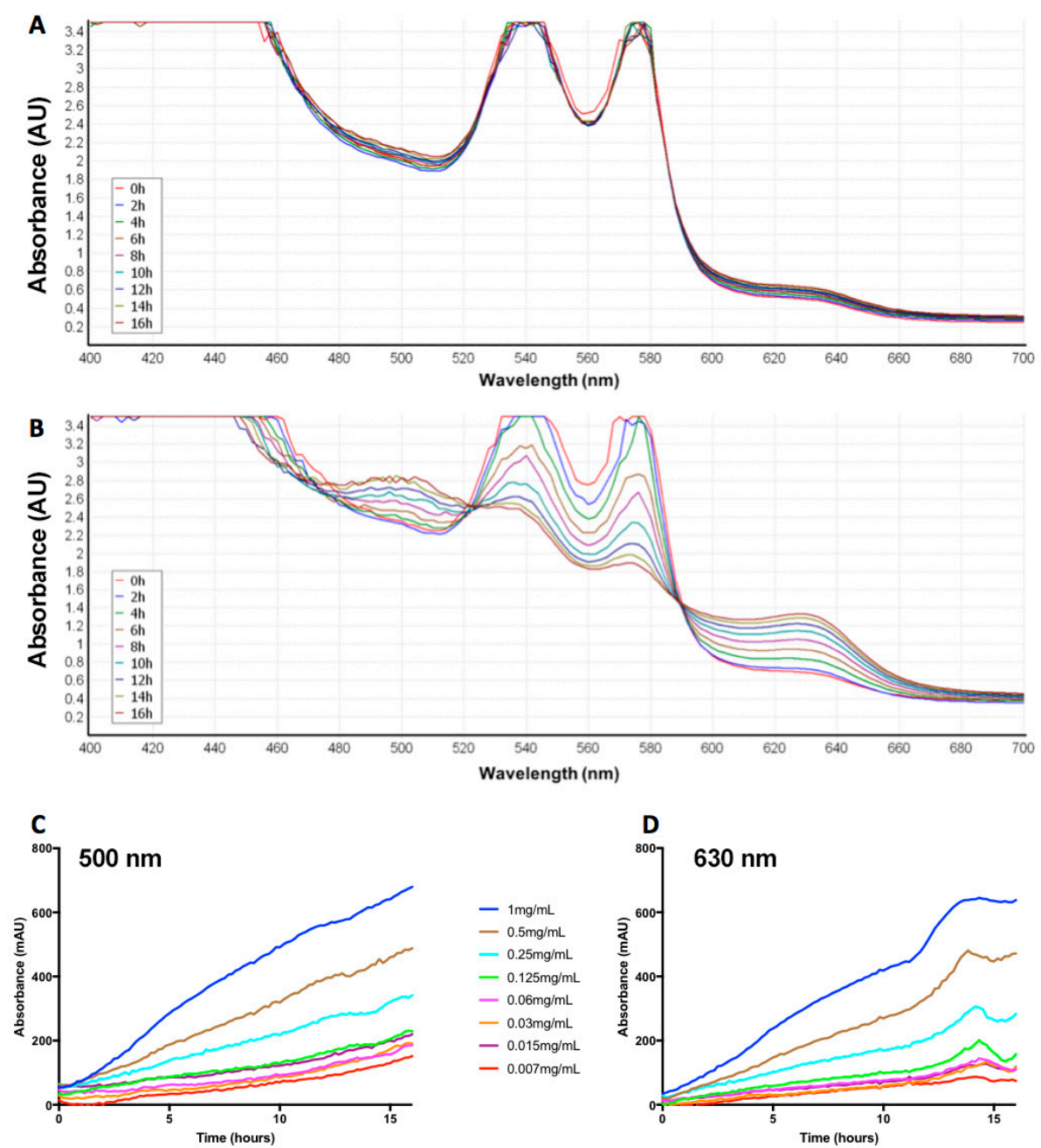

Figure 2. Time- and concentration-dependent changes in absorbance for MetHb over $16 \mathrm{~h}$. Ovine $\mathrm{Hb}$ was incubated with a control (PBS) (A) or N. nigricollis venom $(10 \mathrm{mg} / \mathrm{mL}$ to achieve maximum $\mathrm{MetHb}$ production) (B) at $37^{\circ} \mathrm{C}$ in a plate reader (PHERAStar, BMG Labtech). The absorbance between $400 \mathrm{~nm}$ and $700 \mathrm{~nm}$ was measured every $2 \mathrm{~h}$. The peaks typical of oxygenated $\mathrm{Hb}$ are at $540 \mathrm{~nm}$ and $570 \mathrm{~nm}$, and those of $\mathrm{MetHb}$ are at $500 \mathrm{~nm}$ and $630 \mathrm{~nm}$. Furthermore, the N. nigricollis venom was serially diluted from $1 \mathrm{mg} / \mathrm{mL}$ to $0.007 \mathrm{mg} / \mathrm{mL}$ and mixed with an equal volume of ovine $\mathrm{Hb}$. It was then incubated for $16 \mathrm{~h}$ at $37^{\circ} \mathrm{C}$ in a plate reader (FLUOStar Optima, BMG Labtech) and the absorbance was measured every $2 \mathrm{~h}$ at $500 \mathrm{~nm}$ (C) and $630 \mathrm{~nm}$ (D). The traces shown are representative of three separate experiments, and they were selected to clearly demonstrate the changes in absorbance for $\mathrm{Hb}$ and $\mathrm{MetHb}$ over a period of $16 \mathrm{~h}$. 


\subsection{Heat-Denaturation of N. nigricollis Venom Reduces Its Effect on MetHb Production}

In order to determine whether the ability of $N$. nigricollis venom on MetHb production is dependent on proteins, this venom was heat-denatured prior to using in the assay. The venom was incubated at two different temperatures, $65{ }^{\circ} \mathrm{C}$ and $95{ }^{\circ} \mathrm{C}$ for $10 \mathrm{~min}$ and then cooled to room temperature prior to use in the assay with ovine $\mathrm{Hb}$. Notably, the heat-denatured venom exhibited significantly reduced MetHb production at $16 \mathrm{~h}$ (Figure 3A). This data suggest that $\mathrm{Met} \mathrm{Hb}$ production may be mediated through proteins that are present in the venoms and they are sensitive to heat denaturation.

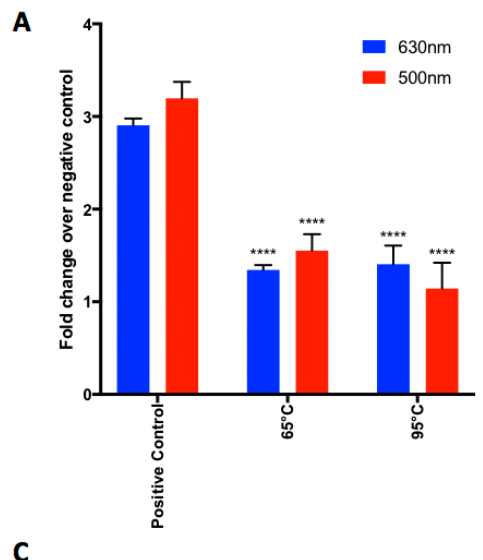

C

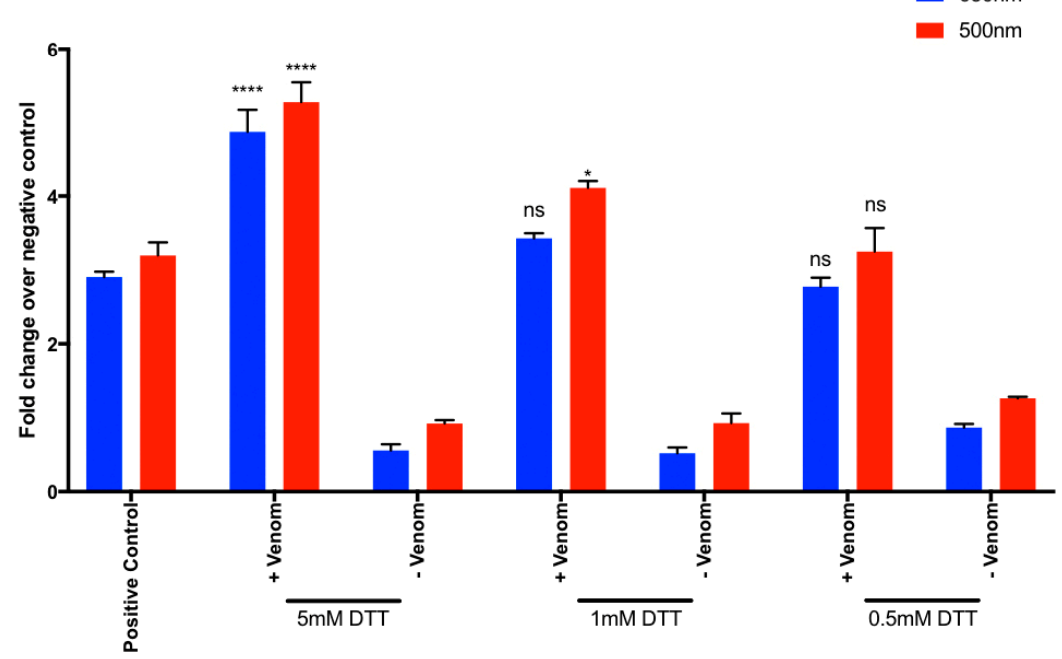

Figure 3. Effect of heat, proteolytic activity of venom and a reducing agent (DTT) on MetHb production. (A) N. nigricollis venom was heat treated at $65{ }^{\circ} \mathrm{C}$ or $95^{\circ} \mathrm{C}$ for $10 \mathrm{~min}$ prior to cooling the venom to room temperature and mixing with ovine $\mathrm{Hb}$. The level of absorbance at $500 \mathrm{~nm}$ and $630 \mathrm{~nm}$ was measured after $16 \mathrm{~h}$. (B) SDS-PAGE (Coomassie stained) gel showing the protein profile of Hb before (as a control) and after incubation with different concentrations of $N$. nigricollis venom for $16 \mathrm{~h}$. Lanes, MW-molecular weight marker, Lane 1 and 4: Venom $(12 \mu \mathrm{g})+$ haemoglobin $(3 \mu \mathrm{g})$. Lane 2 and 5: Venom $(6 \mu \mathrm{g})+$ haemoglobin $(3 \mu \mathrm{g})$. Lane 3 and 6: Venom $(3 \mu \mathrm{g})+$ haemoglobin $(3 \mu \mathrm{g})$. Lanes 1-3; after $16 \mathrm{~h}$ incubation and lanes $4-6$; as controls at $0 \mathrm{~h}$. Lane 7: N. nigricollis venom ( $3 \mu \mathrm{g})$ alone and Lane $8: \mathrm{Hb}(3 \mu \mathrm{g})$ alone. The image shown is representative of three separate experiments. (C) N. nigricollis venom was treated with various concentrations $(0.5 \mathrm{mM}, 1 \mathrm{mM}$ or $5 \mathrm{mM})$ of reducing agent, DTT for $10 \mathrm{~min}$ prior to mixing with ovine $\mathrm{Hb}$ and incubating for another $16 \mathrm{~h}$. The level of absorbance was measured as shown above. Data represent mean $\pm \operatorname{SEM}(n=3)$. The $p$ values shown were as calculated by two-way ANOVA followed by post-hoc Tukey's test using GraphPad Prism $7\left(^{*} p<0.05,{ }^{* *} p<0.01\right.$, ${ }^{* * *} p<0.001$ and $\left.{ }^{* * *} p<0.0001\right)$. The heated (A) or DTT (C)-treated samples were all compared with the respective positive controls (untreated venom), and the negative control used was PBS. 


\subsection{N. nigricollis Venom Does Not Exert Direct Proteolytic Activity on $\mathrm{Hb}$}

To determine whether the MetHb production occurs due to proteolytic actions of N. nigricollis venom on $\mathrm{Hb}$, different concentrations of the venom were incubated with $3 \mu \mathrm{g} \mathrm{Hb}$ overnight along with controls, and these samples were analysed by SDS-PAGE. As shown in Figure 3B, the venom does not have any direct proteolytic activity on $\mathrm{Hb}$ as the bands for this protein are intact and unaffected by increasing concentrations of venom over $16 \mathrm{~h}$ compared to the controls. These data suggest that $N$. nigricollis venom-induced effects on MetHb production are not dependent on direct proteolytic actions of this venom on $\mathrm{Hb}$, although we cannot rule out the possibilities of the effects of this venom on other components that regulate MetHb production.

\subsection{A Reducing Agent Increases the N. nigricollis Venom-Induced MetHb Production}

To assess the impact of a reducing agent on the N. nigricollis venom-induced production of $\mathrm{MetHb}$, 1,4-dithiothreitol (DTT) was used in the assay. The venom was pre-treated with different concentrations of DTT [we chose a range of concentrations (low to high) including $0.5 \mathrm{mM}, 1 \mathrm{mM}$ and $5 \mathrm{mM}$ in order to analyse the maximum impact of this reducing agent on venom-induced MetHb production] and then incubated with ovine $\mathrm{Hb}$. The presence of DTT failed to prevent the oxidation $\mathrm{of} \mathrm{Hb}$, and indeed increased the production of MetHb at the highest concentration $(5 \mathrm{mM})$, although at lower concentrations this increase was not significant (Figure 3C). These data suggest that venom-induced $\mathrm{MetHb}$ production is not diminished by reducing agents such as DTT.

\section{Discussion}

The proteins found within the snake venoms have a multitude of pharmacological actions including direct effects on cells. These include cell lysis or blockade of their functions via binding to a range of receptors and ion channels. They also affect the blood coagulation cascade that is required for effective haemostasis and the cholinergic disruptions to nerve transmission [27,28]. Moreover, a number of snake venoms have been reported to induce direct haemolysis and lead to ischemia $[29,30]$. In this study, we have investigated the effects of a selection of snake venoms on the oxidation of $\mathrm{Hb}$. Most of the snake venoms tested caused at least a minor increase of absorbance at the selected wavelength maxima for $\mathrm{MetHb}$, although the elapids' absorption generally increased to a much lesser extent than the vipers. Despite this, compared to the other viper and elapid venoms, the largest shift observed was for the venom of an elapid, N. nigricollis.

In a previous study [21], Naja naja (Indian Cobra) venom was found to have a greater ability to produce MetHb than two other Indian vipers (Echis carinatus and Daboia russelii). Those results are inconsistent with the findings from this study where many of the viper venoms including Echis carinatus had more pronounced effects than Naja naja venom. Although the reasons for these discrepancies are not entirely clear, they have used human whole blood in their experiments, whereas we have used ovine $\mathrm{Hb}$. Therefore, their experiments may relate more to the ability of venoms to lyse $\mathrm{RBCs}$ (as $\mathrm{Hb}$ would be much more accessible after lysis) than to directly oxidise $\mathrm{Hb}$. We can postulate that single or multiple venom components may act either directly on $\mathrm{Hb}$ or potentially on MetHb reductase to prevent the equilibrium found under healthy natural conditions. A schematic diagram of our working hypothetical model of the impact of venom components on the production of MetHb is shown in Figure 4. 


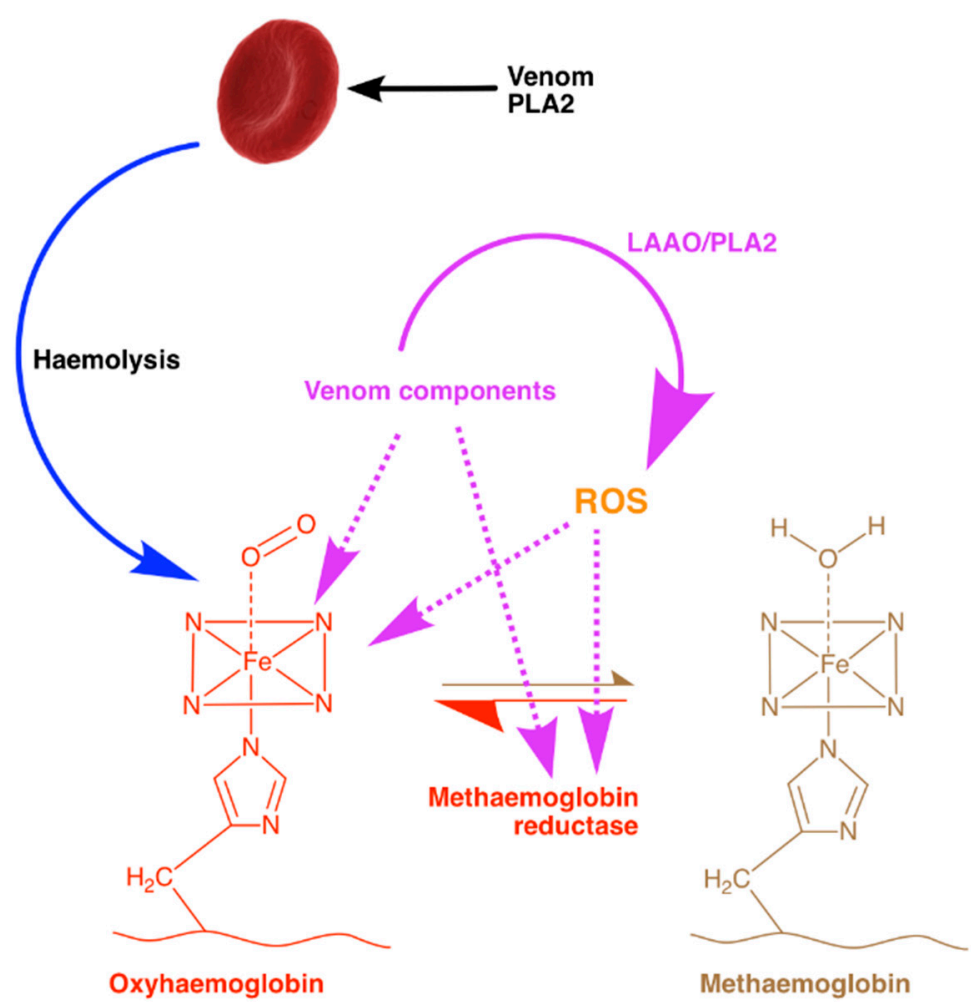

Figure 4. A schematic diagram hypothesising the impact of venom on MetHb production. Haemolysis (the lysing of RBCs) by phospholipase A2 (PLA2) and other venom components is a common effect of snakebite envenoming. In a healthy human, the oxidation of $\mathrm{Hb}$ to $\mathrm{MetHb}$ is constantly combated by an enzyme, MetHb reductase. After certain venomous snakebites, this equilibrium is shifted in favour of MetHb, a toxic species that is also known to be pro-inflammatory. This shift may be a result of the ROS, which is generated as a metabolite of L-amino acid deamination [via L-amino acid oxidases (LAAO)] or lipid peroxidation (via PLA2) present in various venoms. The potential mechanisms for venom-induced changes in MetHb production are shown in the figure as dotted magenta lines.

A previous study using Crotalus molossus nigrescens venom reported that high concentrations of this venom cause some level of proteolytic degradation to $\mathrm{Hb}$ [26]. The same study postulated that the venom's conversion of $\mathrm{Hb}$ to MetHb is due to the oxidative stress induced by $\mathrm{H}_{2} \mathrm{O}_{2}$ which is produced by venom LAAO [26]. It may be possible that following this, $\mathrm{H}_{2} \mathrm{O}_{2}$ then reacts with the ferrous $\mathrm{Hb}$ producing further reactive species via the Fenton reaction [31]. However, N. nigricollis is a snake with potently cytotoxic venom that lacks LAAOs and is composed largely of three-finger toxins $(73.3 \%)$ and PLA2 (21.9\%) [32]. These proteins typically bind to cell membrane components or directly affect the phospholipid bilayer which leads to cell lysis, although they have not been documented interacting directly with $\mathrm{Hb}$. The lack of LAAO and the abundance of PLA2 in N. nigricollis venom supports the theory that the phospholipase activity could be indirectly causing this effect as a result of its oxidative product, arachidonic acid. However, members of the genus Agkistrodon screened for their $\mathrm{Hb}$ oxidising ability (Figure 1) were found to have little or no effects on $\mathrm{Hb}$ despite having a high percentage (31-46\%) of PLA2 [33], more than half of which are enzymatic [34]. There is a very small percentage of group III metalloproteases $(2.4 \%)$ and cysteine-rich secretory proteins (CRiSPs) $(0.2 \%)$ found in N. nigricollis venom [32], components that are also found in viper venoms and are more typically associated with this oxidative effect. The metalloproteases cause multiple pathologies which contribute to oxidative stress including haemorrhage, thereby inducing spontaneous haemolysis, liberating $\mathrm{Hb}$ and free iron. Metalloproteases are also able to induce necrosis [35], releasing myoglobin which has implications on the redox balance. After the degradation of the extra-cellular matrix by metalloproteases, damage-associated molecular patterns 
(DAMPs) are likely to be released, and these can induce further oxidative stress and inflammation [25]. Given the lack of proteases in N. nigricollis venom, the highly cytotoxic PLA2 found in this venom is more likely to be the primary cause of this oxidation. Hydrolysis of the sn-2 acyl bond of plasma membrane glycerophospholipids by PLA 2 releases free fatty acids such as arachidonic acid as well as lysophospholipids and lysophosphatidylcholine, and potentially toxic, ROS [25]. The increase in polyunsaturated fatty acids has also been postulated to cause an increase in lipid peroxidation following administration of a viper (Echis carinatus) venom, and it may be possible that similar peroxidation takes place as a result of $N$. nigricollis venom.

The time- (Figure 2A,B) and concentration- (Figure 2C,D) dependent shift in the absorbance of $\mathrm{Hb} / \mathrm{MetHb}$ by N. nigricollis venom demonstrates that the components of this venom are able to promote the oxidation of $\mathrm{Hb}$. The increase in MetHb production observed over $16 \mathrm{~h}$ and at higher venom concentrations suggests that this effect may increase over time in snakebite victims, and is dependent on the volume of venom injected by the snake. The increase in MetHb production observed with the venom that was treated with the highest concentration of DTT suggests that this effect is actually improved by the addition of a redox reagent. However, at lower concentrations of DTT, this increase was not observed. We originally hypothesised that the addition of a redox reagent such as DTT would prevent the production of ROS, and consequently MetHb by taking the place of antioxidants such as glutathione found naturally in the plasma [36]. The thiol groups of glutathione act as reducing agents in order to prevent the damage to cellular components by ROS. Therefore, the surprising increase in MetHb production with the highest concentration of DTT could be due to the reduction of the tetrameric structure of $\mathrm{Hb}$ and consequently, its enhanced oxidation. The decrease in activity seen with heat treatment of venom provides evidence to suggest that this effect may be due to the proteins present in the venom. The incubation of venom with purified bovine $\mathrm{Hb}$ and further analysis suggest that this effect is not a result of proteolytic degradation of the $\mathrm{Hb}$. However, the results of a previous study using a protease-rich viper venom show that high venom concentrations can lead to proteolytic degradation of $\mathrm{Hb}$. The SDS-PAGE presented here suffers from large protein bands ( 16 kDa) in the crude venom overlapping with the $\mathrm{Hb}$ monomer $(16.1 \mathrm{kDa})$, although it is clear that $\mathrm{Hb}$ is still present. Further investigation using non-reducing or native protein electrophoresis is required to ascertain if there is any degree of proteolysis with $\mathrm{N}$. nigricollis venom on $\mathrm{Hb}$ and to further scrutinise the mechanism of action of this venom on $\mathrm{MetHb}$ production.

Venom-induced neurological and coagulation pathologies have long been the two major areas of interest for scientists to investigate snakebite pathophysiology due to their prominence as the most immediately life-threatening aspects of a snakebite. However, the morbidity is gaining interest recently as estimates of as many as 15,000 people annually suffering amputations as a result of snakebites in sub-Saharan Africa alone [37]. Hence, the disability adjusted life years (DALYs) and loss to any snakebite-afflicted region's work force are of serious importance. ASV is currently the only therapy for snakebite envenoming [4], and while it is effective in saving lives when administered appropriately, it frequently fails to address some of the long-term damage induced by snake venom components. This includes myotoxicity and skeletal muscle damage [38,39] as well as oxidative stress [25], which puts undue pressure on the body that is already suffering from an array of potentially fatal venom-induced health consequences. Following haemolysis caused either directly by the lysis of RBCs or as a result of ROS produced by venom components, $\mathrm{Hb}$ levels are elevated in the blood. As a result, this reduces the oxygen-carrying ability of the blood and decreases its ability to meet the oxygen demand of vital organs. Furthermore, the elevated levels of $\mathrm{Hb}$ cause a reduction in free-haptoglobin levels and can overwhelm the mononuclear phagocytic system, the spleen and eventually the kidneys, which may lead to acute kidney injury [40]. The additional complication of conversion to MetHb could potentially allow this toxic $\mathrm{Hb}$ species to build up and affect the efficiency of the systems in place to reduce free $\mathrm{Hb}$. These complications to the blood would then undoubtedly have further effects on haemostasis and exacerbate existing ischaemic areas, contributing in turn to tissue damage, necrosis and long-term damage from snakebites. 
In conclusion, we have demonstrated that a wide variety of venoms possess $\mathrm{Hb}$-modifying activity among a range of viper and elapid snakes. From the venoms tested, we have observed a significantly higher activity for $\mathrm{N}$. nigricollis venom for the production of MetHb. This effect is likely to be a result of proteins present in the venom, although further fractionation and characterisation is required to identify the exact proteins causing these changes. Moreover, most of the experiments performed in this study used ovine $\mathrm{Hb}$ due to availability. However, future experiments will be performed using human $\mathrm{RBCs}$ and $\mathrm{Hb}$. The clinical significance of venoms on MetHb production and its contribution to envenomation will also be determined in the future. The work highlighting co-administration of melatonin with ASV is worth pursuing further [21], and the use of antioxidants in vivo could potentially be developed further to ascertain whether the oxidative stress can be reduced using flavonoids and their derivatives [41]. Although it may be a less important effect of snakebite envenomation than the immediately life-threatening elements, the reduction of oxidative stress on internal organs and tissues following a snakebite is likely to improve recovery and potentially reduce some of the long-term damage and morbidity as a result.

\section{Materials and Methods}

\subsection{Materials}

The cardiovascular targeted-venom discovery array (Catalogue code: $\mathrm{T}-\mathrm{VDA} \mathrm{CV}^{\mathrm{CV}}$ ) of whole snake venoms was from Venomtech Limited (Sandwich, UK) and ovine blood was obtained from Envigo (UK) Ltd. (Oxon, UK). Clear 96- and 384-well plates were purchased from Greiner (Gloucestershire, $\mathrm{UK}$ ), and DTT, purified bovine $\mathrm{Hb}$, and all other chemicals were from Sigma Aldrich (Dorset, UK)

\subsection{Ovine RBC Lysis and Hb Production}

Ovine blood was lysed by the addition of two volumes of ultrapure water followed by centrifugation $(5000 \times \mathrm{g})$, and the clear supernatant was collected and used in further assays as ovine $\mathrm{Hb}$. Although this supernatant is likely to have other components from RBCs, the presence of a prominent $\mathrm{Hb}$ band was confirmed by SDS-PAGE prior to using this as a $\mathrm{Hb}$ source in further functional assays.

\subsection{Screening of Venoms for MetHb Producing Activity}

The whole snake venoms from the T-VDA ${ }^{\mathrm{CV}}$ array were diluted in $1 \times$ PBS (Fisher Scientific, Loughborough, UK) $(0.2 \mathrm{mg} / \mathrm{mL})$ and mixed with an equal volume of ovine $\mathrm{Hb}$ (diluted 1:2 in $1 \times \mathrm{PBS}$ ) with a final assay volume of $100 \mu \mathrm{L}$ in a 96-well micro titre plate. These samples were then incubated at $37^{\circ} \mathrm{C}$ and the absorbance at $500 \mathrm{~nm}$ and $630 \mathrm{~nm}$ was measured at $16 \mathrm{~h}$ by spectrofluorimetry (FLUOstar Optima, BMG Labtech, Aylesbury, UK).

\subsection{Time- and Concentration-Dependent Effect of N. nigricollis Venom on MetHb Production}

Ovine $\mathrm{Hb}$ diluted (1:2) in $1 \times$ PBS was incubated with $N$. nigricollis venom (at $10 \mathrm{mg} / \mathrm{mL}$ or a range of concentrations between $1 \mathrm{mg} / \mathrm{mL}$ and $0.007 \mathrm{mg} / \mathrm{mL}$ ) or PBS (a negative control) in a 384-well plate. Plates were incubated at $37^{\circ} \mathrm{C}$ in a plate reader (PHERAStar, BMG Labtech, Aylesbury, UK) and the absorbance spectrum between $400 \mathrm{~nm}$ and $700 \mathrm{~nm}$ was measured at 2-h intervals over $16 \mathrm{~h}$. After this time, maximum $\mathrm{Hb}$ oxidisation appeared to be reached, and therefore, this time point was chosen for other experiments in this study. Moreover, to determine the impact of heat and a reducing agent, venom was heat-treated $\left(65^{\circ} \mathrm{C}\right.$ or $95^{\circ} \mathrm{C}$ in a dry bath) or treated with a reducing agent, DTT $(0.5 \mathrm{mM}, 1 \mathrm{mM}$ or $5 \mathrm{mM})$ prior to using them in assays. The temperatures $\left(65^{\circ} \mathrm{C}\right.$ or $\left.95^{\circ} \mathrm{C}\right)$ were determined based on our previous experience in denaturing venom proteins and using them in functional assays. DTT was specifically selected as this is a less toxic and volatile compared to $\beta$-mercaptoethanol; moreover, DTT prevents the reoxidisation of disulfide bonds in proteins. 


\subsection{Sodium Dodecyl Sulfate-Polyacrylamide (SDS-PAGE) Gel Electrophoresis}

The SDS-PAGE analysis was performed according to standard procedures as described previously [42]. The samples were taken before and after incubating a range of concentrations of venom with purified bovine $\mathrm{Hb}$ (Sigma Aldrich, Dorset, UK) at $37^{\circ} \mathrm{C}$ for $16 \mathrm{~h}$. Samples taken prior to 16-h incubation were used as controls to compare the impact of venom on $\mathrm{Hb}$ before and after the incubation. These samples were mixed with reducing sample treatment buffer (Bio-Rad, Watford, UK) and run on a pre-made (Bio-Rad, Watford, UK) 10\% SDS-PAGE gel for $40 \mathrm{~min}$ at 150 constant volts. Gels were then stained with Coomassie brilliant blue (Bio-Rad, Watford, UK) for approximately $1 \mathrm{~h}$ on a rocker, before destaining overnight $\left(10 \%\right.$ acetic acid $/ 10 \%$ methanol $\left./ 80 \% \mathrm{H}_{2} \mathrm{O}\right)$.

\subsection{Statistical Analysis}

All statistical analyses were performed using GraphPad Prism 7. $p$-Values were calculated using one-way or two-way ANOVA followed by Tukey's post-hoc multiple comparisons test.

Author Contributions: Conceptualization, P.H., S.T. and S.V.; Data Curation, H.F.W., P.H., D.R., A.B., H.J.L., L.C. and C.W.; Formal Analysis, H.F.W., D.R., H.J.L. and S.V.; Investigation, P.H., A.B., L.C. and C.W.; Methodology, S.T.; Software, S.V.; Supervision, A.B.B., S.T. and S.V.; Writing-Original Draft, H.W., S.T. and S.V.; Writing-Review \& Editing, H.F.W., P.H., A.B.B., S.T. and S.V.

Funding: This research received no external funding.

Acknowledgments: The authors would like to thank the British Heart Foundation for their funding support for author, Divyashree Ravishankar.

Conflicts of Interest: The authors declare no conflict of interest.

\section{References}

1. Kasturiratne, A.; Wickremasinghe, A.R.; de Silva, N.; Gunawardena, N.K.; Pathmeswaran, A.; Premaratna, R.; Savioli, L.; Lalloo, D.G.; de Silva, H.J. The global burden of snakebite: A literature analysis and modelling based on regional estimates of envenoming and deaths. PLoS Med. 2008, 5, e218. [CrossRef] [PubMed]

2. Williams, H.F.; Vaiyapuri, R.; Gajjeraman, P.; Hutchinson, G.; Gibbins, J.M.; Bicknell, A.B.; Vaiyapuri, S. Challenges in diagnosing and treating snakebites in a rural population of Tamil Nadu, India: The views of clinicians. Toxicon 2017, 130, 44-46. [CrossRef] [PubMed]

3. Vaiyapuri, S.; Vaiyapuri, R.; Ashokan, R.; Ramasamy, K.; Nattamaisundar, K.; Jeyaraj, A.; Chandran, V.; Gajjeraman, P.; Baksh, M.F.; Gibbins, J.M. Snakebite and its socio-economic impact on the rural population of Tamil Nadu, India. PLoS ONE 2013, 8, e80090. [CrossRef] [PubMed]

4. Gutiérrez, J.M.; Calvete, J.J.; Habib, A.G.; Harrison, R.A.; Williams, D.J.; Warrell, D.A. Snakebite envenoming. Nat. Rev. Dis. Primers 2017, 3, 17063. [CrossRef] [PubMed]

5. Warrell, D.A. Snake bite. Lancet 2010, 375, 77-88. [CrossRef]

6. Yamazaki, Y.; Morita, T. Snake venom components affecting blood coagulation and the vascular system: Structural similarities and marked diversity. Curr. Pharm. Des. 2007, 13, 2872-2886. [CrossRef] [PubMed]

7. Markland, F.S., Jr.; Swenson, S. Snake venom metalloproteinases. Toxicon 2013, 62, 3-18. [CrossRef]

8. Herrera, C.; Escalante, T.; Voisin, M.-B.; Rucavado, A.; Morazán, D.; Macêdo, J.K.A.; Calvete, J.J.; Sanz, L.; Nourshargh, S.; Gutiérrez, J.M. Tissue localization and extracellular matrix degradation by PI, PII and PIII snake venom metalloproteinases: Clues on the mechanisms of venom-induced hemorrhage. PLoS Negl. Trop. Dis. 2015, 9, e0003731. [CrossRef]

9. de Queiroz, M.R.; de Sousa, B.B.; da Cunha Pereira, D.F.; Mamede, C.C.N.; Matias, M.S.; de Morais, N.C.G.; de Oliveira Costa, J.; de Oliveira, F. The role of platelets in hemostasis and the effects of snake venom toxins on platelet function. Toxicon 2017, 133, 33-47. [CrossRef]

10. Vaiyapuri, S.; Roweth, H.; Ali, M.S.; Unsworth, A.J.; Stainer, A.R.; Flora, G.D.; Crescente, M.; Jones, C.I.; Moraes, L.A.; Gibbins, J.M. Pharmacological actions of nobiletin in the modulation of platelet function. Br. J. Pharmacol. 2015, 172, 4133-4145. [CrossRef] 
11. Vaiyapuri, S.; Hutchinson, E.G.; Ali, M.S.; Dannoura, A.; Stanley, R.G.; Harrison, R.A.; Bicknell, A.B.; Gibbins, J.M. Rhinocetin, a venom-derived integrin-specific antagonist inhibits collagen-induced platelet and endothelial cell functions. J. Biol. Chem. 2012, 287, 26235-26244. [CrossRef] [PubMed]

12. Kini, R.M.; Koh, C.Y. Metalloproteases affecting blood coagulation, fibrinolysis and platelet aggregation from snake venoms: Definition and nomenclature of interaction sites. Toxins 2016, 8, 284. [CrossRef] [PubMed]

13. Donghui, M.; Armugam, A.; Jeyaseelan, K. Cytotoxic potency of cardiotoxin from naja sputatrix: Development of a new cytolytic assay. Biochem. J. 2002, 366, 35-43.

14. Gillissen, A.; Theakston, R.D.G.; Barth, J.; May, B.; Krieg, M.; Warrell, D.A. Neurotoxicity, haemostatic disturbances and haemolytic anaemia after a bite by a tunisian saw-scaled or carpet viper (echis 'pyramidum'-complex): Failure of antivenom treatment. Toxicon 1994, 32, 937-944. [CrossRef]

15. Santhosh, M.S.; Sundaram, M.S.; Sunitha, K.; Kemparaju, K.; Girish, K.S. Viper venom-induced oxidative stress and activation of inflammatory cytokines: A therapeutic approach for overlooked issues of snakebite management. Inflamm. Res. 2013, 62, 721-731. [CrossRef] [PubMed]

16. Katkar, G.D.; Sundaram, M.S.; Hemshekhar, M.; Sharma, D.R.; Santhosh, M.S.; Sunitha, K.; Rangappa, K.S.; Girish, K.S.; Kemparaju, K. Melatonin alleviates echis carinatus venom-induced toxicities by modulating inflammatory mediators and oxidative stress. J. Pineal. Res. 2014, 56, 295-312. [CrossRef] [PubMed]

17. Sebastin Santhosh, M.; Hemshekhar, M.; Thushara, R.M.; Devaraja, S.; Kemparaju, K.; Girish, K.S. Vipera russelli venom-induced oxidative stress and hematological alterations: Amelioration by crocin a dietary colorant. Cell Biochem. Funct. 2013, 31, 41-50. [CrossRef]

18. Rother, R.P.; Bell, L.; Hillmen, P.; Gladwin, M.T. The clinical sequelae of intravascular hemolysis and extracellular plasma hemoglobin: A novel mechanism of human disease. JAMA 2005, 293, 1653-1662. [CrossRef]

19. Mebius, R.E.; Kraal, G. Structure and function of the spleen. Nat. Rev. Immunol. 2005, 5, 606. [CrossRef]

20. Alves, E.C.; Sachett, J.D.A.G.; Sampaio, V.S.; Sousa, J.D.D.B.; Oliveira, S.S.D.; Nascimento, E.F.D.; Santos, A.D.S.; da Silva, I.M.; da Silva, A.M.M.; Wen, F.H.; et al. Predicting acute renal failure in bothrops snakebite patients in a tertiary reference center, western brazilian amazon. PLOS ONE 2018, 13, e0202361. [CrossRef]

21. Sharma, R.D.; Katkar, G.D.; Sundaram, M.S.; Paul, M.; NaveenKumar, S.K.; Swethakumar, B.; Hemshekhar, M.; Girish, K.S.; Kemparaju, K. Oxidative stress-induced methemoglobinemia is the silent killer during snakebite: A novel and strategic neutralization by melatonin. J. Pineal Res. 2015, 59, 240-254. [CrossRef] [PubMed]

22. Costa, T.R.; Burin, S.M.; Menaldo, D.L.; de Castro, F.A.; Sampaio, S.V. Snake venom L-amino acid oxidases: An overview on their antitumor effects. J. Venom. Anim. Toxins 2014, 20, 23. [CrossRef] [PubMed]

23. Lim, S.-K.; Ferraro, B.; Moore, K.; Halliwell, B. Role of haptoglobin in free hemoglobin metabolism. Redox Rep. 2001, 6, 219-227. [CrossRef]

24. Moseley, M.J.; Oenning, V.; Melnik, G. Methemoglobinemia. AJN 1999, 99, 47. [CrossRef] [PubMed]

25. Sunitha, K.; Hemshekhar, M.; Thushara, R.; Santhosh, M.S.; Sundaram, M.S.; Kemparaju, K.; Girish, K. Inflammation and oxidative stress in viper bite: An insight within and beyond. Toxicon 2015, 98, 89-97. [CrossRef] [PubMed]

26. Meléndez-Martínez, D.; Muñoz, J.M.; Barraza-Garza, G.; Cruz-Peréz, M.S.; Gatica-Colima, A.; Alvarez-Parrilla, E.; Plenge-Tellechea, L.F. Rattlesnake crotalus molossus nigrescens venom induces oxidative stress on human erythrocytes. J. Venom. Anim. Toxins 2017, 23, 24. [CrossRef]

27. Mackessy, S.P. Handbook of Venoms and Toxins of Reptiles; CRC Press: Boca Raton, FL, USA, 2010.

28. Fry, B.G. Venomous Reptiles and Their Toxins: Evolution, Pathophysiology and Biodiscovery; Oxford University Press: New York, NY, USA, 2015.

29. Fernandez, M.L.; Quartino, P.Y.; Arce-Bejarano, R.; Fernandez, J.; Camacho, L.F.; Gutierrez, J.M.; Kuemmel, D.; Fidelio, G.; Lomonte, B. Intravascular hemolysis induced by phospholipases a2 from the venom of the eastern coral snake, micrurus fulvius: Functional profiles of hemolytic and non-hemolytic isoforms. Toxicol. Lett. 2018, 286, 39-47. [CrossRef]

30. Lenske, E.; Padula, A.M.; Leister, E.; Boyd, S. Severe haemolysis and spherocytosis in a dog envenomed by a red-bellied black snake (pseudechis porphyriacus) and successful treatment with a bivalent whole equine igg antivenom and blood transfusion. Toxicon 2018, 151, 79-83. [CrossRef]

31. Winterbourn, C.C. Toxicity of iron and hydrogen peroxide: The fenton reaction. Toxicol. Lett. 1995, 82, 969-974. [CrossRef] 
32. Petras, D.; Sanz, L.; Segura, Á.; Herrera, M.; Villalta, M.; Solano, D.; Vargas, M.; León, G.; Warrell, D.A.; Theakston, R.D.G. Snake venomics of african spitting cobras: Toxin composition and assessment of congeneric cross-reactivity of the pan-african echitab-plus-icp antivenom by antivenomics and neutralization approaches. J. Proteome Res. 2011, 10, 1266-1280. [CrossRef]

33. Lomonte, B.; Tsai, W.-C.; Ureña-Diaz, J.M.; Sanz, L.; Mora-Obando, D.; Sánchez, E.E.; Fry, B.G.; Gutiérrez, J.M.; Gibbs, H.L.; Sovic, M.G.; et al. Venomics of new world pit vipers: Genus-wide comparisons of venom proteomes across agkistrodon. J. Proteomics 2014, 96, 103-116. [CrossRef] [PubMed]

34. Jia, Y.; Ermolinsky, B.; Garza, A.; Provenzano, D. Phospholipase $A_{2}$ in the venom of three cottonmouth snakes. Toxicon 2017, 135, 84-92. [CrossRef] [PubMed]

35. Gutiérrez, J.M.A.; Romero, M.; Núñez, J.; Chaves, F.; Borkow, G.; Ovadia, M. Skeletal muscle necrosis and regeneration after injection of $\mathrm{BaH} 1$, a hemorrhagic metalloproteinase isolated from the venom of the snake Bothrops asper (Terciopelo). Exp. Mol. Pathol. 1995, 62, 28-41. [CrossRef] [PubMed]

36. Finkel, T.; Holbrook, N.J. Oxidants, oxidative stress and the biology of ageing. Nature 2000, 408, 239. [CrossRef] [PubMed]

37. Chippaux, J.-P. Estimate of the burden of snakebites in sub-saharan africa: A meta-analytic approach. Toxicon 2011, 57, 586-599. [CrossRef]

38. Gutiérrez, J.M.; León, G.; Rojas, G.; Lomonte, B.; Rucavado, A.; Chaves, F. Neutralization of local tissue damage induced by bothrops asper (Terciopelo) snake venom. Toxicon 1998, 36, 1529-1538. [CrossRef]

39. Jayawardana, S.; Gnanathasan, A.; Arambepola, C.; Chang, T. Chronic musculoskeletal disabilities following snake envenoming in sri lanka: A population-based study. PLoS Negl. Trop. Dis. 2016, 10, e0005103. [CrossRef]

40. Kumar, K.G.S.; Narayanan, S.; Udayabhaskaran, V.; Thulaseedharan, N.K. Clinical and epidemiologic profile and predictors of outcome of poisonous snake bites - an analysis of 1,500 cases from a tertiary care center in malabar, north kerala, india. Int. J. General Med. 2018, 11, 209-216. [CrossRef]

41. Sachetto, A.T.A.; Rosa, J.G.; Santoro, M.L. Rutin (quercetin-3-rutinoside) modulates the hemostatic disturbances and redox imbalance induced by bothrops jararaca snake venom in mice. PLoS Negl. Trop. Dis. 2018, 12, e0006774. [CrossRef]

42. Vaiyapuri, S.; Harrison, R.A.; Bicknell, A.B.; Gibbins, J.M.; Hutchinson, G. Purification and functional characterisation of rhinocerase, a novel serine protease from the venom of bitis gabonica rhinoceros. PLoS ONE 2010, 5, e9687. [CrossRef] 